\title{
Ostvarenje proračuna općina, gradova i županija u 2018. i 2019. ${ }^{I}$
}

\author{
KATARINA OTT, MiHAELA BRONIĆ, BRANKO STANIĆ, FILIP BADOVINAC
}

Cilj ovoga rada je na što jednostavniji način, na temelju baze podataka Ministarstva financija, sistematizirati i prikazati osnovne podatke o ostvarenju proračuna svih hrvatskih lokalnih jedinica ${ }^{2}$, njihovim prihodima $i$ rashodima3, te suficitu/deficitu za 20I8. i 20I9. godinu. Tako se uz pomoć ovog teksta i tabela koje se nude u Excel formatu zainteresirani mogu upoznati s financijskim stanjem svih općina, gradova i županija u te dvije godine te ih usporedivati sa stanjem u proteklim godinama. ${ }^{4}$

Ministarstvo financija svake godine objavljuje podatke o ostvarenju proračuna svih lokalnih jedinica. ${ }^{5}$ Riječ je o brojnim i sadržajem obimnim tabelama u kojima se građani ne mogu lako snalaziti, pa Institut za javne financije iz godine u godinu objavljuje jednostavne i sistematizirane analize ključnih podataka. Uz podatke Ministarstva financija i analize Instituta, obilje se korisnih podataka može pronaći i na mrežnim stranicama lokalnih jedinica. No, svi se ti podatci moraju vrlo oprezno i koristiti i interpretirati.

Prvo, zbog nadležnosti za prikupljanje različitih vrsta prihoda i pružanje različitih vrsta javnih dobara i usluga ne mogu se uspoređivati iznosi općina, gradova i županija, već samo općina s općinama, gradova s gradovima i županija sa županijama. Dodatno, zainteresirani mogu, primjerice, zbrojiti prihode ili rashode po stanovniku svoje općine ili grada i svoje županije i tako saznati koliko se ukupno na lokalnoj razini prikuplja i troši po stanovniku te općine ili grada. Iznimka je Zagreb - istovremeno i grad i županija - pa njegovi stanovnici trebaju gledati samo podatke za Zagreb.

Drugo, visoki prihodi - kako ukupni, tako i po stanovniku - ne moraju nužno značiti i dobro poslovanje lokalne jedinice, jer ponekad veliki dio njihovih prihoda čine razne vrste pomoći, zaduživanja i slično. U

I Ovaj tekst nastao je u okviru projekta „Isplati li se transparentnost? Politički i socioekonomski učinci transparentnosti proračuna lokalnih jedinca u Hrvatskoj” (IP-2019-04-8360) koji financira Hrvatska zaklada za znanost (HRZZ). Mišljenja, nalazi, zaključci i preporuke su autorski i ne odražavaju nužno stajališta HRZZ-a.

${ }^{2}$ U ovome tekstu naziv „lokalne jedinice” podrazumijeva županije, gradove i općine, a „lokalni proračuni” se odnose na proračune županija, gradova i općina.

${ }^{3}$ Analiza obuhvaća samo prihode i rashode, bez primitaka i izdataka. Prihodi i rashodi se odnose na poslovanje te prodaju i nabavu nefinancijske imovine (npr. zemljišta, građevinski objekti, koncesija, prijevoznih sredstava, itd.), a primitci i izdatci na financijsku imovinu, uzimanje, davanje i otplate zajmova. Detaljnije u Ott i sur. (2009).

${ }_{4}^{4}$ Podatci za sve općine, gradove i županije u 20I8. i 20I9. dostupni su u Excel tablici, a za prethodne godine u Ott i Bronić (2015) te

Ott, Bronić i Stanić (20I6, 20I8a, 20I8b). O njihovoj proračunskoj transparentnosti vidi poveznicu.

5 Podatci za razdoblje 1995--2019. dostupni su na mrežnim stranicama Ministarstva financija. 
takvim slučajevima potrebno je dodatno istražiti te prihode (namjenu, izvor, uvjete pod kojima su dani). Primjerice, 20I8. godine razne vrste pomoći od države činile su 75\% ukupnih prihoda općine Ervenik. Isto je i s izdacima, suficitima i deficitima koji u jednoj godini mogu biti iznimno visoki.

Treće, sâm proračun ne mora uvijek odražavati stvarno financijsko stanje lokalnih jedinica, jer se one ponekad ne zadužuju samo kroz proračun, nego i preko pravnih osoba čiji su većinski vlasnici/suvlasnici, te ustanova kojih su osnivači. Primjerice za gradnju sljemenske žičare nije se zadužio samo Grad Zagreb nego i Zagrebački holding. Zbog toga bi se za realnije utvrđivanje stvarnog financijskog stanja lokalnih jedinica moralo uvijek analizirati i podatke o prihodima i rashodima te imovini, kapitalu i obvezama pravnih osoba u njihovom vlasništvu/suvlasništvu i ustanova kojih su osnivači.

Četvrto, u nekim lokalnim jedinicama postoje velike razlike prihoda i rashoda po godinama. Pri objašnjenju tih razlika treba biti oprezan. Često je neophodno pretražiti i mrežne stranice lokalnih jedinica (naročito ako objavljuju narativna obrazloženja ključnih proračunskih dokumenata), lokalnih medija i/ili kontaktirati lokalne izvršne ili zakonodavne vlasti. U određenoj su godini lokalne jedinice, primjerice, mogle prodati vrijednu kapitalnu imovinu (npr. zemljišta ili zgrade), naplatiti iznimno visoke i neuobičajene iznose komunalnih doprinosa, imati velika kapitalna ulaganja (npr. za lokalne ceste ili sportske objekte) financirane kreditima i/ili pomoćima EU, prenijeti viškove ili manjkove prihoda i primitaka iz prethodnih godina i sl. Na primjer, općina Konavle je 20I7. ostvarila I,7 mil. kn prihoda od komunalnog doprinosa, 20I8. čak I4,5 mil. kn. Prihodi od komunalnog doprinosa 20I8. uglavnom su povećani zbog rekonstrukcija i dogradnji u Zračnoj luci Dubrovnik, a to je onda utjecalo i na povećanje ukupnih prihoda te općine.

\section{OSNOVNA ANALIZA UKAZUJE NA SLJEDEĆE:}

\section{ProsJečni UKUPNI PRIHOdi, PROSJEČNI PRIHODI PO STANOVNIKU, PROSJEČNI UKUPNI SUFICIT/DEFICIT}

- Grafikon I pokazuje porast prosječnih ukupnih prihoda svih vrsta lokalnih jedinica u razdoblju od 20I6. - 20I9. te izražene razlike u visini prosječnih ukupnih prihoda na razini županija, gradova ${ }^{6} \mathrm{i}$ općina. Primjerice, ostvareni prosječni ukupni prihodi županija u 20I9. su oko 225 mil. kn, gradova sa Zagrebom oko I5O mil. kn, gradova bez Zagreba oko 93 mil. kn, a općina I3 mil. kn.

- U 20I8. i 2019. značajnije rastu i prosječni prihodi po stanovniku, koji su slični u gradovima i općinama, no znatno niži u županijama (grafikon 2). Na primjer, prosječni prihodi po stanovniku 20I9. u općinama i gradovima iznose oko 5.000 do $6.000 \mathrm{kn}$, a u županijama manje od $1.500 \mathrm{kn}$.

- Povećava se broj općina i gradova s većim prihodima po stanovniku, posebice u 20I8. i 2019. (grafikon 3). Najveći broj gradova i općina 20I8. i 20I9. ostvaruje godišnje između 3.000 i $6.000 \mathrm{kn}$ prihoda po stanovniku. Razlog povećanja prihoda po stanovniku trebalo bi detaljnije istražiti, ali vjerojatno je i posljedica novog sustava fiskalnog izravnanja koji se primjenjuje od 2OI8. U 2019. je primjerice manje od II\% općina i samo tri grada (Duga Resa, Oroslavje, Donja Stubica), ali i sve županije, ostvarilo manje od $3.000 \mathrm{kn}$ prihoda po stanovniku. No, mali je broj i lokalnih jedinica s više od 9.000 kn prihoda po stanovniku (u 20I9. samo oko II\% općina i I3\% gradova, a prethodnih godina još i manje).

- Prosječni ukupni suficit/deficit oscilira, pri čemu se 2019. stanje pogoršava, odnosno suficiti se smanjuju, a deficiti povećavaju (grafikon 4). Zbog veličine svog proračuna, ukupnim deficitima najviše pridonosi Grad Zagreb, no on se s deficitom od 56I kn po stanovniku 2019., nalazi daleko iza Općine Medulin ( $7.245 \mathrm{kn}$ deficita po stanovniku) ili Grada Nina (4.643 kn deficita po stanovniku). Visoki iznosi deficita određene godine ne moraju nužno značiti loše poslovanje lokalne jedinice, pa valja dodatno istražiti razloge. Moguće je da su baš te godine rashodi neuobičajeno visoki jer je nabavljena visokovrijedna dugotrajna imovina (škola, sportska dvorana, zemljište, cesta, javna rasvjeta) koja će se financirati iz kredita.

\footnotetext{
${ }^{6}$ Iako Grad Zagreb ima status i grada i županije, odnosno obavlja poslove iz nadležnosti i gradova i županija, u ovoj se analizi uključuje u izračun prosjeka za gradove.
}

2 NEWSLETTER I2O | K. OTT i sur. I Ostvarenje proračuna općina, gradova i županija u 20I8. i 2org. | Institut za javne financije 
Grafikon I. Prosječni ukupni prihodi 2016. - 2019. (u mil. kn)

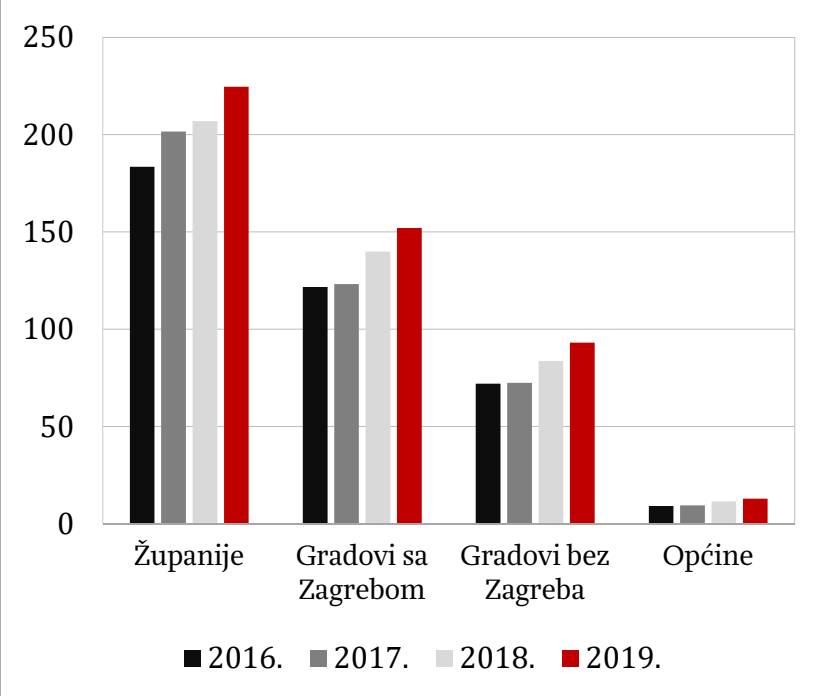

Izvor: Ministarstvo financija (2O2O)

Grafikon 3. Distribucija prihoda po stanovniku 2016. - 2019. (\% lokalnih jedinica)

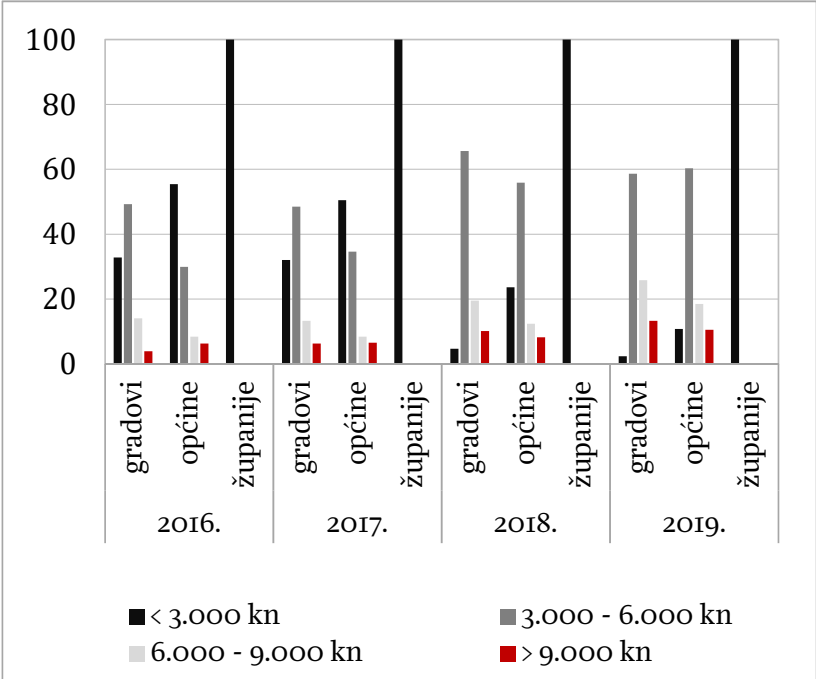

Izvor: Ministarstvo financija (2O2O)
Grafikon 2. Prosječni prihodi po stanovniku* 20I6. - 20I9. (u tis. kn)

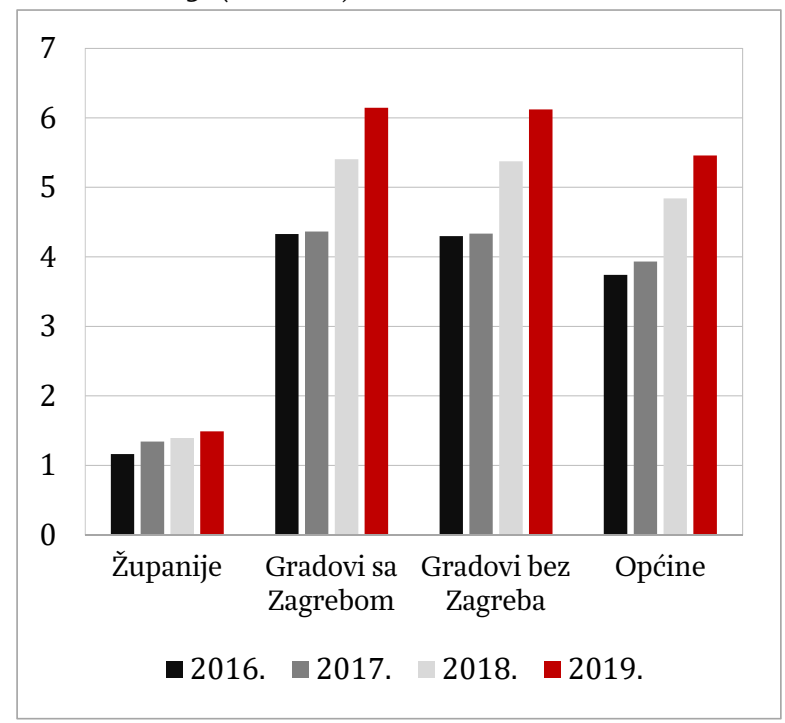

Izvor: Ministarstvo financija (2020)

Grafikon 4. Prosječni ukupni suficit/deficit 20I6. - 2019. (u mil. kn)

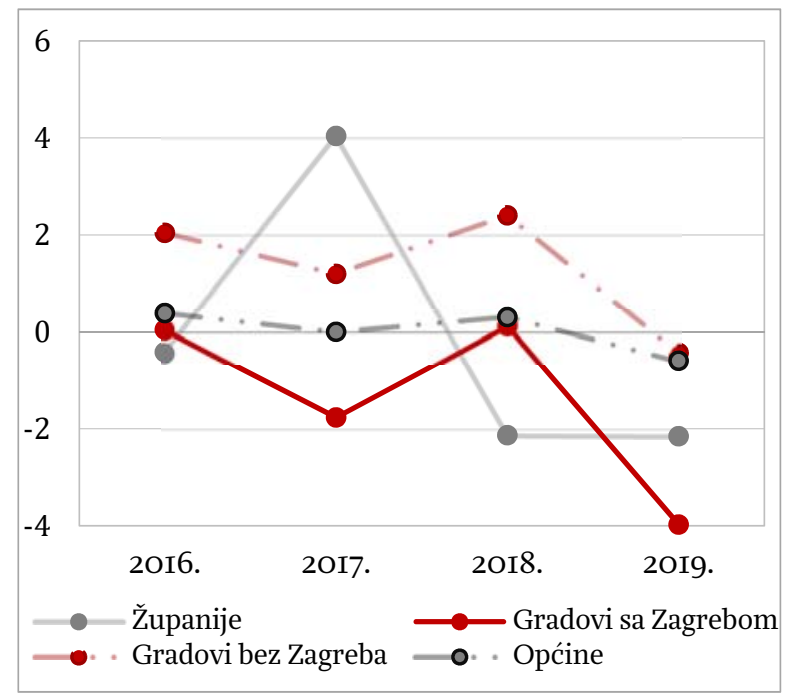

Izvor: Ministarstvo financija (2O2O)

\section{UTJECAJ GEOGRAFSKOG POLOŽAJA NA FINANCIISKO STANJE OPĆINA I GRADOVA}

I ova analiza ponovno ukazuje da je za financijsko stanje općina i gradova najčešće presudan položaj uz obalu:

- Ako se promatraju općine s prosječnim prihodima po stanovniku većim od Io.ooo kn, 20I8. se od njih 27 samo sedam ne nalaze uz more (Civljane, Ervenik, Lećevica, Saborsko, Promina, Grožnjan i Lokvičići), a 2019. od njih 33 samo devet (Civljane, Grožnjan, Saborsko, Lećevica, Ervenik, Biskupija, Kijevo, Vrhovine i Fužine).

- S druge strane, među općinama s prosječnim prihodima po stanovniku manjim od 2.90o kn, 20I8. se od njih 85 ni jedna ne nalazi uz more, a 2019. od njih 39 ni jedna.

- Od 20 gradova s najvećim prosječnim prihodima po stanovniku, 20I8. ih se čak I8 (svi osim Zagreba i Obrovca) nalazi uz more, a 2OIg. ih je I4 uz more. S druge strane, od 20 gradova s najmanjim prihodima po stanovniku 20I8. su samo Kaštela uz more, a 20I9. baš ni jedan. 


\section{RAZILIKE MEĐU LOKALNIM JEDINICAMA}

- Velike su razlike između najbogatijih i najsiromašnijih općina, pa su u obje promatrane godine ukupni prihodi, primjerice, općine Medulin jednaki zbroju ukupnih prihoda 25 najsiromašnijih općina.

- U obje su godine ukupni prihodi Grada Zagreba veći od zbroja ukupnih prihoda oko I2O gradova.

- Dva grada (Opuzen i Komiža) 2019. imaju ukupne prihode manje od I3 mil. kn, dok pet općina (Medulin, Matulji, Konavle, Viškovo i Kostrena) ima ukupne prihode veće od 50 mil. kn.

- 54 gradova ili općina je 20I9. imalo veće prihode po stanovniku od Grada Zagreba (9.427 kn).

- Velike su razlike u broju stanovnika općina: 52 ih ima manje od tisuću (najmanje su Civljane sa I29, Lanišće s 25I i Kijevo s 256), dok ih 33 ima od pet do deset tisuća, a šest (Viškovo, Podstrana, Nedelišće, Matulji, Brdovec i Čepin) i više od deset tisuća stanovnika.?

- Oko $45 \%$ lokalnih jedinica je 20I9. imalo suficit (II županija, 6I grad i I85 općina), a 20I8. njih gotovo 60\% (I2 županija, 8I grad i 249 općina). Najveći su suficit 20I9. ostvarili Varaždinska županija (24,4 mil. kn), Grad Rijeka (69,6 mil.kn) te Općina Baška Voda (9,3 mil. kn), a najveći deficit Virovitičko-podravska županija (43,5 mil. kn), Grad Zagreb (453,6 mil. kn) i Općina Medulin (5I,9 mil. kn).

Sinteza podataka ponuđena u Excel tablicama, kao i ova kratka tekstualna analiza, ispunit će svoju svrhu ukoliko potaknu širu javnost da dodatno prouči bogate baze podataka Ministarstva financija i svojih lokalnih jedinica. Na taj će se način moći podrobnije informirati o prikupljanju i trošenju novca iz lokalnih proračuna i učiniti dodatni korak prema daljnjem jačanju transparentnosti lokalnih proračuna. Valja se nadati da će javnost - uz već postojeće brojne vodiče, vizualizacije i aplikacije koje lokalne jedinice objavljuju na svojim mrežnim stranicama ${ }^{8}$ - iskoristiti i ovu analizu za dodatno upoznavanje s proračunskim temama i sudjelovanje u lokalnim proračunskim procesima.

Također se valja nadati da će ova kratka analiza - kao i niz prethodnih analiza Instituta - zainteresirati Vladu, nadležna ministarstva, Sabor i saborske odbore koji će se kad-tad morati suočiti s problemom "teritorijalne rascjepkanosti i funkcionalne raspodjele nadležnosti lokalnih jedinica"9 te reformirati teritorijalni i fiskalni ustroj države. Ako već ne svojom voljom, onda zasigurno zbog sve učestalijih zahtjeva Europske komisije.

\footnotetext{
${ }^{7}$ Podatci za općine i gradove prema procjeni broja stanovnika DZS-a za 2019. Podatci za županije prema procjeni broja stanovnika sredinom godine 20I9.

${ }^{8}$ Vidi Ott i sur. (2020).

${ }^{9}$ Vidi Europska komisija (2O2O).

4 NEWSLETTER I2O | K. OTT i sur. I Ostvarenje proračuna općina, gradova i županija u 20I8. i 20I9. I Institut za javne financije
} 